\title{
O DRIBLE CONTINENTAL: A MARGEM DE APRECIAÇÃO NACIONAL NA DECISÃO DE CONVENCIONALIDADE DO CRIME DE DESACATO PELO SUPERIOR TRIBUNAL DE JUSTIÇA
}

\author{
THE CONTINENTAL BYPASS: THE NATIONAL MARGIN OF \\ APPRECIATION IN THE DECISION OF THE BRAZILIAN SUPERIOR \\ COURT OF JUSTICE THAT RULED IN FAVOR OF THE \\ CONVENTIONALITY OF THE CRIME OF CONTEMPT OF A PUBLIC \\ OFFICIAL
}

\author{
Gustavo Rabay Guerra \\ Universidade Federal da Paraíba - UFPB - (João Pessoa, PB, Brasil) \\ Centro Universitário de João Pessoa - Unipê - (João Pessoa, PB, Brasil) \\ Henrique Jerônimo Bezerra Marcos \\ Universidade Federal da Paraíba - UFPB - (João Pessoa, PB, Brasil)
}

Recebimento: 30 abr. 2018

Aceitação: 14 jul. 2018

\begin{abstract}
Como citar este artigo / How to cite this article (informe a data atual de acesso / inform the current date of access):
GUERRA, Gustavo Rabay; MARCOS, Henrique Jerônimo Bezerra. O drible continental: a margem de apreciação nacional na decisão de convencionalidade do crime de desacato pelo Superior Tribunal de Justiça. Revista da Faculdade de Direito UFPR, Curitiba, PR, Brasil, v. 63, n. 2, p. 169-189, ago. 2018. ISSN 2236-7284. Disponível em: $<$ https://revistas.ufpr.br/direito/article/view/59194>. Acesso $\quad$ em: $30 \quad$ ago. $2018 . \quad$ DOI: http://dx.doi.org/10.5380/rfdufpr.v63i2.59194.
\end{abstract}

\section{RESUMO}

Este trabalho tem por objetivo analisar os fundamentos da decisão do Superior Tribunal de Justiça (STJ) no Habeas Corpus 270.269-MS, no que toca à convencionalidade do crime de desacato, especificamente em relação à utilização da técnica da Margem de Apreciação para relativizar a vinculação do Brasil com normas internacionais de direitos humanos. Inicialmente, o trabalho demonstra a relação entre a liberdade de expressão, a democracia e o crime de desacato. Passa então, a apresentar a decisão do STJ. Em seguida, passa ao estudo da Margem de Apreciação. Com estes dados, o trabalho examina a decisão do STJ e apresenta críticas à validade da aplicação da técnica pelo Tribunal. O trabalho aponta para uma dimensão crítica acerca do emprego da técnica na decisão examinada, em razão de ter sido desconsiderada a própria estrutura do instituto, bem como a jurisprudência da Corte Interamericana de Direitos Humanos. Observa, também, que decisões judiciais que restringem a liberdade de expressão ao convalidar a punição do crime de desacato podem contribuir para o aumento da desconfiança no papel democrático do Poder Judiciário brasileiro.

PALAVRAS-CHAVE

Liberdade de expressão. Desacato. Margem de apreciação. Corte Interamericana de Direitos Humanos. 


\begin{abstract}
The purpose of this paper is to analyze the grounds of the decision of the Brazilian Superior Court of Justice (STJ) in Habeas Corpus 270,269-MS, regarding the conventionality of the crime of "desacato" (contempt of a public official), specifically in relation to the use of the Margin of Appreciation technique to relativize the linkage with international human rights standards. Initially, the work demonstrates the relationship between freedom of expression, democracy and the crime of contempt. It then goes on to present the decision of the STJ. After that, it starts to study the Margin of Appreciation. With these data, the work examines the decision of the STJ and criticizes the validity of the application of the technique by the Brazilian Court. The work points to a critical dimension regarding the use of the technique in the decision examined, pointing that the structure of the institute itself, as well as the jurisprudence of the Inter-American Court of Human Rights, was disregarded. It also notes that judicial decisions that restrict freedom of speech by validating the punishment of the crime of contempt may contribute to increasing distrust of the democratic role of the Brazilian Judiciary.
\end{abstract}

\title{
KEYWORDS
}

Freedom of speech. Contempt. Margin of appreciation. Inter-American Court of Human Rights.

\section{INTRODUÇÃO}

O presente artigo tem por objetivo analisar os fundamentos da decisão no Habeas Corpus 270.269-MS, emitida pela Terceira Seção do Superior Tribunal de Justiça (STJ) em 2017, a respeito da declaração de convencionalidade do crime de desacato (art. 331 do Código Penal). Em especial, pretende examinar os argumentos utilizados na decisão para aplicação da técnica denominada Margem de Apreciação e, por meio desta, relativizar a incidência de normas estabelecidas pela Convenção Americana de Direitos Humanos, além da jurisprudência da Corte Interamericana de Direitos Humanos.

Nestes termos, o problema da presente pesquisa é condensado no seguinte questionamento: é juridicamente válida a utilização da técnica da Margem de Apreciação pelo STJ em sede do Habeas Corpus 270.269-MS? A hipótese levantada por esta pesquisa é a de que a decisão é juridicamente inválida por utilização incorreta da técnica e pelo fato de o Brasil estar sujeito ao Sistema Interamericano de Direitos Humanos, que não adota a técnica nos mesmos moldes que o Sistema Europeu.

Não obstante, observa-se que, apesar da relevância da discussão, longe de propor uma solução moral à questão da legitimidade da punição pela prática do crime de desacato, o presente trabalho se limita ao estudo da utilização da Margem de Apreciação pelo STJ na referida decisão, em cotejo com as interpretações do instituto realizadas pela Cortes Interamericana e Europeia de Direitos Humanos. 
Nessa senda, primeiramente é apresentada a relação entre a democracia e a liberdade de expressão no contexto contemporâneo, além da relação destas com a punição pelo crime de desacato. Em seguida, o trabalho passa à análise da decisão tomada pelo STJ, em especial seus fundamentos e a justificação para a aplicação da Margem de Apreciação ao caso concreto.

Em seguida, o trabalho passa a considerar a técnica em si, notadamente sua utilização pela Corte Europeia e Interamericana de Direitos Humanos e suas características definidoras. Com estes dados, o trabalho permite uma compreensão das razões pelas quais a utilização da técnica na decisão da corte brasileira foi realizada de forma questionável, conforme será apresentado.

\section{A LIBERDADE DE EXPRESSÃO ENQUANTO POSTULADO DEMOCRÁTICO E O CRIME DE DESACATO}

Sem ignorar a relevância de outros atos normativos e políticos, pode-se dizer que a promulgação da Constituição de 1988 marcou, formalmente, a ruptura do modelo de Estado de exceção então vigente no Brasil. A Carta coroou os movimentos de transição, do regime autoritário em direção ao que se entende contemporaneamente como Estado de direito (SOUZA NETO; SARMENTO, 2014, p. 170).

Neste novo sistema adota-se a democracia como uma das cláusulas de maior relevância normativa, constituindo princípio jurídico-constitucional com dimensões materiais, procedimentais e legitimadoras; a democracia é impulso dirigente de todo arcabouço jurídico brasileiro (CANOTILHO, 1998, p. 277-278). Desta cláusula geral, surgem princípios que compartilham estatura constitucional: soberania popular, cidadania, dignidade da pessoa humana, igualdade e liberdade. Em que pese estes possuírem hierarquia congênere no atual modelo normativo, é possível argumentar que, filosoficamente, todos eles são tributários da compreensão contemporânea do que é democracia (KELSEN, 2000, p. 27).

Não obstante, tal diálogo nem sempre é livre de controvérsias; conforme Habermas (2001, p. 766-767), a própria ideia de Estado democrático de direito se apresenta por vezes como uma união paradoxal de princípios contraditórios. É possível argumentar que tais contradições vêm de sua própria linguagem; a extensão dos direitos humanos, como aponta Villey (2007, p. 5-7), é incerta em razão da própria indeterminação de suas formulações.

Neste sentido, o autor aponta o que, em seu entendimento, seria um exemplo da contradição inata dos direitos humanos; é o caso, por exemplo, da liberdade de expressão: "Mais uma promessa 
impossível! E seria errado deduzir daí que serão toleráveis as provocações às violências racistas ou os falsos testemunhos” (VILLEY, 2007, p. 6).

Ocorre que, a partir da constatação de que os direitos não são absolutos, mas apenas relativos, conclui-se que é preciso que eles sejam compatibilizados com os demais valores normativos incorporados pelo Estado (ALEXY, 2011, p. 287). Sendo assim, por meio de técnicas de solução de colisões entre direitos humanos, é possível determinar seu conteúdo e solucionar tais controvérsias mediante a aplicação da proporcionalidade enquanto faceta de concretização da justiça. Delimita-se, então, o alcance dos valores em conflito e soluciona-se a controvérsia (SCHLINK, 2012, p. 719).

Neste aspecto, a liberdade de expressão não é diferente de qualquer outro direito. Trata-se de um direito relativo e poderá, então, ser limitado quando em conflito com outro direito. Veja-se o voto do Justice Oliver Wendell Holmes Jr. no caso Schenck v. United States, de 1919, da Suprema Corte estadunidense: um homem que, mentindo, grita “fogo” em um salão lotado, causando pânico e o consequente pisoteio das pessoas alvoroçadas pelo falso incêndio, não está em exercício legítimo de seu direito de liberdade de expressão (MEIKLEJOHN, 1961, p. 258).

Sendo assim, é possível que a liberdade de expressão seja constringida em sua relação com outros direitos. Por outro lado, em razão da especial relevância da liberdade de expressão para o Estado de Direito - em especial a compreensão do “[...] carácter instrumental da liberdade de expressão em ordem à protecção da autodeterminação democrática da comunidade política da preservação da soberania popular” (MACHADO, 2002, p. 255-256) -, é preciso que a ação estatal que restrinja seu exercício seja bem justificada com fim de garantir legitimidade jurídica à tal exceção. Quanto mais caro é o direito, mais o agente estatal que o constringe precisa fundamentar sua decisão (BARBOSA MOREIRA, 1988, p. 84).

Isso porque, no sistema normativo ao qual o Brasil está submetido, a liberdade de expressão é estabelecida não só na já mencionada Constituição de $1988^{1}$, mas em diversos documentos internacionais de direitos humanos, em especial na Convenção Americana de Direitos Humanos (Pacto de São José da Costa Rica de 1969)². O destaque para este diploma se dá porque, além de signatário ao tratado, o Brasil reconheceu a jurisdição da Corte Interamericana de Direitos Humanos ${ }^{3}$. Nesses termos, tem-se que o Brasil reconhece o direito à liberdade de expressão e, portanto, em princípio estaria proibido de tolher seu exercício por parte de seus jurisdicionados.

\footnotetext{
${ }^{1}$ Cf. o Artigo $5^{\circ}$ da Constituição, incisos IV, V, VI, e o Artigo 220 e seguintes do mesmo diploma.

${ }^{2}$ Cf. o Artigo 13 da referida Convenção, em especial seus parágrafos primeiro, segundo e terceiro.

${ }^{3}$ O Brasil aderiu à Convenção Americana de Direitos Humanos em 1992, mas somente em 1998 é que o Brasil reconheceu a jurisdição obrigatória da Corte Interamericana de Direitos Humanos. Entretanto, apenas em 2002 é que o Poder Executivo promulgou o Decreto 4.463/02, reconhecendo a jurisdição do tribunal internacional em território brasileiro.
} 
Ao mesmo tempo, o Estado estabelece que a prática de desacato é criminosa, ou seja, é crime a conduta de desacatar funcionário público no exercício da função ou em razão dela. Trata-se de tipo penal previsto no Artigo 331 do Código Penal, dentro do Título XI - "Dos Crimes Contra a Administração Pública” -, no Capítulo II - "Dos Crimes Praticados por Particular Contra a Administração em Geral”.

Compreende-se por desacato a conduta de desrespeitar, afrontar, menosprezar ou humilhar funcionário público no exercício de sua função. Desse modo, é caracterizado como crime comum quanto ao sujeito ativo (ou seja, pode ser cometido por qualquer pessoa). Para se configurar, é preciso que seja praticado contra funcionário público em razão de sua função pública; praticado contra agente público, mas em razão de sua conduta particular, não se trata mais do crime de desacato, mas sim de crime contra a honra. No mais, quanto ao sujeito passivo, compreende-se que este é, primariamente, o Estado (o ente público), e apenas em nível secundário, o próprio funcionário público (GRECO, 2017, p. 1.698-1.700).

Alguns argumentam que a punição de atos desta natureza é, na realidade, uma forma de censura e, portanto, uma restrição ilegítima da liberdade de expressão. Este direito, por natureza, existe para assegurar a liberdade de comunicar ideias e opiniões controversas e, em geral, repudiadas pelos detentores do poder. Em outras palavras, a expressão de posicionamentos condizentes com os interesses dominantes não é o objetivo de se estabelecer um direito de liberdade de expressão (SARMENTO, 2007, p. 36). A liberdade de expressão existe para garantir o direito de se dizer o que as autoridades nem sempre querem ouvir.

Outrossim, em um Estado como o Brasil que, como dito, acaba de sair de um momento de profundo desrespeito aos direitos fundamentais, o tipo penal pode ser interpretado como uma forma indireta de censura. A punição de críticas ao Estado consideradas como prática de desacato inibiria o funcionamento democrático da comunidade por restringir a participação popular no escrutínio dos funcionários públicos. Trata-se do "efeito inibidor" (chilling effect): não se critica com medo da possível punição (RAMOS, 2017, p. 685).

Além de que, é de se pontuar que o diploma que criminaliza a prática do desacato foi promulgado durante o regime autoritário do Estado Novo (GOMES; GONÇALVES, 2016, p. 82). Nesse sentido, observa-se que algumas pesquisas apontam o papel de conivência adotado por algumas instâncias do Judiciário brasileiro em chancelar a prática de censura à imprensa na ditadura militar brasileira (CARVALHO, 2014, p. 95). A censura por meio do Judiciário, desse modo, não é uma excentricidade à prática nacional. 
Por sua vez, posicionamento contrário (favorável à validade do crime de desacato) aponta que a punição do ilícito não pode ser considerada censura, existindo apenas para proteger de menoscabo o agente público e toda a Administração Pública e, deste modo, assegurar interesse geral da sociedade no bom funcionamento do Estado. Argumenta-se, assim, que o tipo penal protege a honra da Administração e do agente público, não podendo, então, ser considerado violação do direito à liberdade de expressão que tem seu exercício limitado ao direito à honra do funcionário (BALTAZAR JUNIOR, 2017, p. 340).

\section{A DECISÃO DO SUPERIOR TRIBUNAL DE JUSTIÇA RECONHECENDO A MARGEM DE APRECIAÇÃO BRASILEIRA}

A questão da legitimidade da punição do crime de desacato não é pacífica, sua discussão teórica, política e social está longe de ser solucionada. Tanto é assim que, em intervalo de menos de um ano, o Superior Tribunal de Justiça, em exercício de controle de convencionalidade nacional ${ }^{4}$, decidiu pela incompatibilidade do tipo penal desacato com a Convenção Americana de Direitos Humanos (decisão unânime de dezembro de 2016 pela Quinta Turma) e, posteriormente, modificou seu entendimento decidindo que a punição pela sua prática era convencional, ou seja, juridicamente válida (decisão de junho de 2017 da Terceira Seção) ${ }^{5}$.

A decisão que importa para o presente trabalho é precisamente a que sentencia pela compatibilidade entre o dispositivo penal e a Convenção. De todo modo, tem-se que na primeira decisão a Quinta Turma do STJ decidiu pela inconvencionalidade do crime, afastando a condenação no caso concreto. Em seus fundamentos menciona expressamente a existência de recomendações emitidas pela Comissão Interamericana de Direitos Humanos, bem como o risco que o crime de desacato causa ao pleno exercício da liberdade de expressão (BRASIL, 2016).

Ocorre que, como já mencionado, em acórdão de 2017, a Terceira Seção do STJ superou o precedente e reconheceu a compatibilidade do tipo penal; o desacato voltou a ser crime. Nesta decisão, o Tribunal afastou as alegações de incompatibilidade entre a Convenção Americana de Direitos Humanos, afirmando que: (i) não existem decisões concretas e vinculantes tomadas na Corte

\footnotetext{
${ }^{4}$ Semelhante ao controle de constitucionalidade, o controle de convencionalidade é um juízo de parametricidade entre a normativa nacional e as normas internacionais, em especial, a Convenção Americana de Direitos Humanos. Trata-se de instrumento pelo qual o órgão jurisdicional (nacional ou internacional) declara uma norma compatível ou incompatível com as normas de Direito Internacional dos Direitos Humanos (LIRA, 2016, p. 32).

${ }^{5}$ O Superior Tribunal de Justiça é composto por três Seções especializadas. Cada Seção tem duas Turmas; a Terceira Seção se divide na Quinta e Sexta Turmas, que se ocupam, entre outros temas, do julgamento de matéria criminal e de direitos humanos.
} 
Interamericana de Direitos Humanos a respeito do tema, (ii) as eventuais recomendações exaradas pela Comissão Interamericana de Direitos Humanos ${ }^{6}$ não teriam força decisória, mas apenas instrutória e, por fim, (iii) ainda que existissem decisões da Corte Interamericana a respeito do tema, estas não seriam suficientes para elidir a autonomia do Estado brasileiro, afinal, o Brasil possui uma margem de apreciação pautada em sua soberania (BRASIL, 2017).

Tendo em vista a singular característica dos fundamentos acima mencionados, faz-se referência direta aos excertos de maior representatividade do acórdão:

[...] 6. Com efeito, as recomendações expedidas pela CIDH não possuem força vinculante, mas tão somente "poder de embaraço" ou "mobilização da vergonha”. 7. Embora a Comissão Interamericana de Direitos Humanos já tenha se pronunciado sobre o tema "leis de desacato", não há precedente da Corte relacionada ao crime de desacato atrelado ao Brasil. [...] 15. Ainda que existisse decisão da Corte (IDH) sobre a preservação dos direitos humanos, essa circunstância, por si só, não seria suficiente a elidir a deliberação do Brasil acerca da aplicação de eventual julgado no seu âmbito doméstico, tudo isso por força da soberania que é inerente ao Estado. Aplicação da Teoria da Margem de Apreciação Nacional (margin of appreciation). [...] Nessa toada, atraindo essa conjuntura à situação em concreto, tem-se que o crime de desacato não pode, sob qualquer viés, seja pela ausência de força vinculante às recomendações expedidas pela CIDH, como já explanado, seja pelo viés interpretativo, o que merece especial importância, ter sua tipificação penal afastada. Nada obstante, ainda que existisse decisão da Corte (IDH) sobre a preservação dos direitos humanos, essa circunstância, por si só, não seria suficiente a elidir a deliberação do Brasil acerca da aplicação de eventual julgado no seu âmbito doméstico, tudo isso por força da soberania inerente ao Estado. [...] (BRASIL, 2017, p. 2, 3, 45).

Desse modo, vê-se que, em seus fundamentos, o STJ afirma que mesmo que houvesse uma decisão específica da Corte Interamericana, esta não impediria a possibilidade de o Brasil, pautado em sua soberania, decidir acerca da aplicação deste julgado em seu âmbito doméstico. Afinal, de acordo com os fundamentos do Tribunal, o Brasil possui Margem de Apreciação nacional. Referenciando a técnica da Margem de Apreciação, o STJ entende possível a superação de eventual decisão internacional da Corte Interamericana de Direitos Humanos.

\section{A TÉCNICA DA MARGEM DE APRECIAÇÃO NA PRÁTICA INTERNACIONAL}

Doutrinariamente, a Margem de Apreciação é compreendida como uma técnica judicial a ser utilizada por cortes internacionais; trata-se de um mecanismo de autocontenção utilizado pelos tribunais internacionais com o propósito de garantir a natureza subsidiária da jurisdição internacional. Desse modo, técnica é derivada da natureza eminentemente secundária das cortes internacionais - a

\footnotetext{
${ }^{6}$ O Sistema Interamericano de Direitos Humanos é composto por dois microssistemas: (i) o da Organização dos Estados Americanos - OEA, encabeçado por um órgão consultivo, a Comissão Interamericana dos Direitos Humanos e (ii) o microssistema da Convenção Americana de Direitos Humanos, encabeçado pela Corte Interamericana dos Direitos Humanos, uma instituição judicial autônoma.
} 
ideia de que as entidades internacionais devem agir em segundo plano, apenas quando a inabilidade do Estado é reconhecida (CAROZZA, 2003, p. 38).

Assim, a Margem de Apreciação é utilizada quando a corte internacional entende que é melhor que o Estado decida, por si mesmo, determinado caso concreto. Desse modo, conclui-se que esta “remessa de competência” parte, necessariamente, da jurisdição internacional. Isto é, aplicar ou não a Margem de Apreciação é uma decisão da corte internacional em deferência à corte nacional em razão da subsidiariedade da jurisdição daquela (VILA, 2017, p. 393).

Não obstante, apesar de a subsidiariedade ser regra comum tanto ao Sistema Interamericano quanto ao Sistema Europeu de Direitos Humanos, a Margem de Apreciação é um instituto propriamente europeu (TRINDADE, 1999, p. 125). Foi criado pela extinta Comissão Europeia de Direitos Humanos e, posteriormente, adotado pela Corte Europeia de Direitos Humanos (GREER, 2000, p. 5) ${ }^{7}$.

De todo modo, parte dos internacionalistas tem grande consideração pelo desenvolvimento da técnica. Defendem que é dos Estados o poder-dever de decidir seus conflitos por meio de seus instrumentos democráticos. Os sistemas internacionais de direitos humanos devem ser mantidos em segundo plano, como uma rede de proteção e não como um substituto perene da autoridade interna dos Estados (HOFFMANN, 2009).

Mais que isso, os defensores da Margem de Apreciação argumentam que as decisões tomadas pelo Estado são naturalmente mais democráticas que as decisões impostas por uma autoridade exterior tal como uma corte internacional. Nesse sentido, defendem, ainda, que, comparadas com as cortes internacionais, as autoridades nacionais estão em uma melhor posição para considerar os fatos envolvidos em um caso judicial ocorrido em seu território (GREER, 2000, p. 33).

Similarmente, compreende-se que, para alcançar uma proporcionalidade entre legalidade e o processo democrático, ou seja, para se possibilitar um desenvolvimento normativo em um Estado, é preciso que a jurisdição internacional se mantenha em segundo plano. Nem sempre é possível alcançar uma solução jurídica por meio de uma análise legal pura e direta dos interesses em conflito. Em determinados casos é de se garantir certo grau de razoabilidade e ponderação; de acordo com os defensores da técnica, este juízo deveria ser realizado com base nas características culturais de uma comunidade (LETSAS, 2006, p. 724).

\footnotetext{
${ }^{7}$ Não havia qualquer previsão expressa da técnica no texto original da Convenção Europeia de Direitos Humanos. Sua implementação legal ocorreu apenas com o Protocolo 15 do Conselho da Europa, que estabelece em seu artigo $1^{\circ}$ que os Estados-parte, em conformidade com o princípio da subsidiariedade da jurisdição internacional, estão autorizados a agir de acordo com uma "margem de apreciação" sob a supervisão da Corte Europeia de Direitos Humanos (COUNCIL OF EUROPE, 2013).
} 
Afinal, tendo em vista que inexiste um consenso apriorístico sobre a extensão dos direitos humanos, os defensores da Margem de Apreciação alegam que - diante desta falta de precisão -, em situações em que não há um grau substancial de concordância sobre qual direito em conflito deve prevalecer, a prerrogativa para decidir a questão deve ser dos Estados (HUTCHINSON, 1999, p. 640).

Em suma, a ideia por trás da Margem de Apreciação é a de que a prerrogativa para decidir os casos de direitos humanos nos quais não há um consenso internacional estabelecido deve ser dos Estados, por meio de seus agentes políticos eleitos e seus processos democráticos nacionais.

De outra banda, a Margem de Apreciação também é alvo de críticas por muitos que enxergam na técnica uma contradição da universalidade dos direitos humanos. Compreende-se que, em si, a Margem de Apreciação é prejudicial aos desígnios do processo internacional de direitos humanos e, em especial, ao controle de convencionalidade, tendo em vista que o propósito da existência deste mecanismo é assegurar um controle imparcial, universal e contramajoritário do Direito Internacional dos Direitos Humanos (RAMOS, 2016, p. 184-185).

No entanto, não há que se dizer que os críticos da Margem de Apreciação defendem a abolição da natureza subsidiária das cortes internacionais; não se questiona que, na maioria das vezes, é admissível que os casos judiciais iniciem e encerrem dentro da jurisdição nacional (GROSS; AOLÁIN, 2001, p. 649).

O problema com o instituto transparece porque a Margem de Apreciação não é apenas uma manifestação da natureza subsidiária da jurisdição internacional; caso seja levada ao extremo, a técnica redundaria na extinção do próprio sistema internacional. Afinal, na contramão da universalidade, a Margem de Apreciação ratifica as interpretações nacionalistas do Direito Internacional, o que, por sua vez, compromete a uniformidade mundial dos direitos humanos.

\section{CRÍTICAS À INTERPRETAÇÃO DA TÉCNICA DA MARGEM DE APRECIAÇÃO NA DECISÃO DO SUPERIOR TRIBUNAL DE JUSTIÇA}

Seja pela defesa ou pela crítica ao instituto, tem-se que a utilização apropriada da Margem de Apreciação ocorre em relação à jurisdição internacional. É dizer: a técnica é um mecanismo utilizável pelas instâncias internacionais - é a corte internacional (em especial, a Corte Europeia de Direitos Humanos) que, enquanto julga um caso, decide pela utilização da Margem de Apreciação na situação concreta (PARRAS, 2015, p. 8).

Essa é uma conclusão aparentemente incontroversa. Afinal, falar em aplicação nacional da Margem de Apreciação é, no mínimo, um pleonasmo. Quando a jurisdição estatal interpreta normas 
internacionais e decide um caso, é evidente que está realizando uma interpretação pautada em sua apreciação nacional.

Toda interpretação se realiza de acordo com as preconcepções subjetivas de seu intérprete. Nesta senda, de acordo com Hans-Georg Gadamer (2004, p. 398), tentar escapar das próprias concepções não é só impossível, mas também absurdo. A interpretação significa precisamente trazer à baila as próprias concepções para que o significado do texto possa ser feito à medida do intérprete. Deste modo, parece ser redundante falar que uma decisão estatal se deu de acordo com a Margem de Apreciação nacional.

Nesse sentido, como visto acima, a Margem de Apreciação aparece apenas quando a corte internacional, ao analisar o caso, entende por bem autorizar que o Estado mantenha sua decisão nacional, haja vista que se trata de um caso em que não existe consenso internacional e que, portanto, deve ser decidido de acordo com as particularidades domésticas. Assim, frise-se, trata-se de um juízo realizado pela corte internacional quando o caso já se encontra devidamente internacionalizado. Não há que se falar de aplicação da Margem de Apreciação ainda em nível nacional.

Assim o sendo, apresenta-se o primeiro aspecto problemático da decisão da Terceira Seção do Superior Tribunal de Justiça (BRASIL, 2017). A Margem de Apreciação, enquanto técnica de contenção da jurisdição internacional, não pode ser aplicada pela corte estatal. Trata-se de instrumento à disposição da corte internacional que, com base em seu juízo próprio, considera ser permitido (ou não) ao Estado, naquele caso concreto, decidir com base em suas aferições e particularidades nacionais. Em outras palavras, ao Superior Tribunal de Justiça, enquanto instância de jurisdição nacional, não cabe decidir a respeito da aplicação ou não da Margem de Apreciação.

A Margem de Apreciação não existe para ser utilizada pelo Estado. Seu emprego ocorre quando o caso se encontra judicializado internacionalmente. Neste momento, o papel do Estado é o de um mero peticionante, devendo alegar perante a corte internacional que naquele caso concreto não existe um consenso geral sobre o tema e, portanto, convencer a corte internacional de abrir mão de sua competência e permitir ao Estado decidir com base em suas particularidades nacionais.

Ademais, outra controvérsia que pode ser apontada na decisão do STJ diz respeito à submissão do Estado brasileiro à jurisdição da Corte Interamericana de Direitos Humanos. Isso porque percebe-se que a Margem de Apreciação é um instituto próprio do Sistema Europeu de Direitos Humanos e, como sabido, o Brasil encontra-se vinculado ao Sistema Interamericano de Direitos Humanos. Desse modo, é de se questionar a respeito da possibilidade da Margem de Apreciação neste último sistema. 
Em que pese Cançado Trindade afirmar que a técnica não possui expressividade no Sistema Interamericano - "felizmente, tal doutrina não encontra um desenvolvimento paralelo explícito na jurisprudência sob a Convenção Americana sobre Direitos Humanos” (TRINDADE, 1999, p. 125) -, é possível reconhecer a presença de, ao menos, uma iteração tímida da Margem de Apreciação neste sistema.

Trata-se da Opinião Consultiva 4/84 emitida pela Corte Interamericana de Direitos Humanos, proferida a pedido da Costa Rica e que versa a respeito de propostas de emendas constitucionais que regulamentam o processo de naturalização deste Estado. Em suas conclusões, a Corte Interamericana reconheceu que existem alguns temas reservados ao domínio da legislação nacional e que nesses temas é de se reconhecer uma "margem de apreciação" aos Estados. Nos termos utilizados pela Corte:

[...] partiendo de la base de la esencial unidad de la dignidad del ser humano, es posible apreciar circunstancias en que los imperativos del bien común puedan justificar un mayor o menor grado de distinciones que no se aparten de las consideraciones precedentes. Se trata de valores que adquieren dimensiones concretas a la luz de la realidad en que están llamados a materializarse y que dejan un cierto margen de apreciación para la expresión que deben asumir en cada caso. (CORTE INTERAMERICANA DE DIREITOS HUMANOS, 1984, p. $16)^{8}$.

Assim o sendo, é possível reconhecer que existe ao menos uma hipótese na qual, no Sistema Interamericano de Direitos Humanos, foi reconhecido a um Estado-parte o direito a uma "margem de apreciação”. No entanto, verifica-se, também, que há uma diferença quantitativa e qualitativa na aplicação da técnica.

Isto é, ainda que se reconheça que existe propriamente uma Margem de Apreciação no Sistema Interamericano, é de se conceder que ela transparece de forma limitada e restrita se comparada à versão europeia (LIRA, 2016, p. 59). Com efeito, na própria Opinião Consultiva 4/84 a Corte Interamericana já demonstrou uma preocupação com o excesso de discricionariedade estatal, afirmando que a aplicação desta “margem de apreciação” deve ocorrer de forma restritiva (CÔRREA, 2013, p. 277).

Similarmente, no caso Artavia Murillo e Outros v. Costa Rica a Corte Interamericana rechaçou a tentativa do Estado de se utilizar da teoria da Margem de Apreciação como argumento de defesa. Referenciando a jurisprudência da Corte Europeia de Direitos Humanos, a Corte

\footnotetext{
8 “[...] a partir da base da unidade essencial da dignidade do ser humano, é possível apreciar circunstâncias nas quais os imperativos do bem comum podem justificar um grau maior ou menor de distinções que não se desviam das considerações precedentes. Estes são valores que adquirem dimensões específicas à luz da realidade em que são chamados a materializar e que deixam uma certa margem de apreciação pela expressão que devem assumir em cada caso.” (tradução nossa).
} 
Interamericana esclareceu que o uso da técnica não pode ser ilimitado (CORTE INTERAMERICANA DE DIREITOS HUMANOS, 2012, p. 74). Mais que isso, nos termos da decisão, ressaltou que “[...] a Corte não considera pertinente se pronunciar sobre as alegações do Estado em relação a que contaria com uma margem de apreciação para estabelecer proibições como a efetuada [...]” (CORTE INTERAMERICANA DE DIREITOS HUMANOS, 2012, p. 98).

Desse modo, é possível concluir que, ainda que se reconheça a possibilidade de aplicação da Margem de Apreciação no Sistema Interamericano, sua aplicação resta limitada a casos de relevância reduzida, notadamente, dentro das lacunas estabelecidas pelas normas internacionais de direitos humanos e, em especial, desde que compatível com a jurisprudência da Corte Interamericana (LOPES SALDANHA; MORAIS BRUM, 2015, p. 221).

Em face desta restrição, verifica-se uma segunda controvérsia na decisão da Terceira Seção do Superior Tribunal de Justiça. Ignorando por completo a reduzida amplitude de eventual Margem de Apreciação Interamericana, o tribunal brasileiro, em um drible continental, fundamenta seu acórdão no instituto como se, no Sistema Interamericano de Direitos Humanos, a Margem de Apreciação tivesse o mesmo grau de aplicação que no Sistema Europeu de Direitos Humanos.

Destarte, desconsiderando a jurisprudência da Corte Interamericana, o STJ utiliza-se da técnica de forma ampla, alcançando, inclusive, matérias de elevado grau de importância para os direitos humanos: a limitação e a potencial criminalização de condutas que, ao menos indiretamente, se relacionam à liberdade de expressão.

Outrossim, tem-se que, ao fundamentar sua decisão, o tribunal brasileiro menciona que não existem precedentes concretos e vinculantes tomados na Corte Interamericana de Direitos Humanos a respeito do tema e, além disso, observa que eventuais recomendações exaradas pela Comissão Interamericana de Direitos Humanos não teriam força decisória, mas apenas instrutória (BRASIL, 2017, p. 45) Ocorre que quanto aos dois fundamentos a decisão do Superior Tribunal de Justiça está incorreta.

Existem manifestações da Corte e da Comissão Interamericana de Direitos Humanos a respeito do crime de desacato. Nesse sentido, é de se mencionar a Declaração de Princípios sobre Liberdade de Expressão de 2000, emitida pela Comissão Interamericana, em que se reconheceu que a criminalização do desacato é atentatória à liberdade de expressão: “As leis que punem a expressão ofensiva contra funcionários públicos, geralmente conhecidas como ‘leis de desacato’, atentam contra a liberdade de expressão e o direito à informação” (ORGANIZAÇÃO DOS ESTADOS AMERICANOS, 2000). 
Outrossim, na jurisprudência da Corte Interamericana de Direitos Humanos já existe precedente em que se considerou a tipificação criminal do desacato incompatível com a Convenção Americana de Direitos Humanos, por ofensa à garantia de liberdade de expressão. Trata-se do caso Palamara Iribarne vs. Chile, em que a Corte reconheceu que o desacato fora utilizado de forma desproporcional, privando o direito de liberdade de expressão do indivíduo e, consequentemente, impedindo o adequado funcionamento do processo democrático daquele Estado. Nas palavras da Corte Interamericana:

La Corte considera que la legislación sobre desacato aplicada al señor Palamara Iribarne establecía sanciones desproporcionadas por realizar críticas sobre el funcionamiento de las instituciones estatales y sus miembros, suprimiendo el debate esencial para el funcionamiento de un sistema verdaderamente democrático y restringiendo innecesariamente el derecho a la libertad de pensamiento y de expresión. (CORTE INTERAMERICANA DE DIREITOS HUMANOS, 2005, p. 61) ${ }^{9}$.

Assim, não é possível afirmar que inexistem precedentes no Sistema Interamericano de Direitos Humanos a respeito da criminalização do desacato. Por outro lado, é possível argumentar que, à primeira vista, as hipóteses acima mencionadas não são vinculantes ao Brasil. Afinal, no caso da Comissão tem-se uma Declaração com natureza jurídica de soft law ${ }^{10}$, ou seja, cujo valor normativo é limitado (GUZMAN; MEYER, 2010, p. 222). No caso da Corte Interamericana, em que pese a decisão ser compulsória, o Brasil não era parte e, portanto, não estaria vinculado àquela decisão ${ }^{11}$.

Ainda assim, não se pode concluir que sobre estes precedentes não existe um valor jurídico determinante ao Estado brasileiro. Isso porque, ao reconhecer a existência do posicionamento da Corte e da Comissão Interamericana e (apesar disso) atuar em sentido contrário, tem-se que o Brasil está violando a boa-fé internacional. Foi assim que entendeu a Corte Interamericana no caso Loayza Tamayo vs. Perú, reconhecendo o dever dos Estados-parte de cumprirem as obrigações internacionais com boa-fé, inclusive aquelas exaradas pela Comissão Interamericana (que, tecnicamente, teriam apenas caráter de Recomendação):

\footnotetext{
9 “A Corte considera que a legislação de desacato aplicada ao Sr. Palamara Iribarne estabeleceu sanções desproporcionadas por criticar o funcionamento das instituições estaduais e seus membros, suprimindo o debate essencial para o funcionamento de um sistema verdadeiramente democrático e restringindo desnecessariamente o direito à liberdade de pensamento e expressão.” (tradução nossa).

${ }^{10}$ Nos termos do artigo 41 da Convenção Americana de Direitos Humanos, a atuação da Comissão Interamericana de Direitos Humanos é não vinculante, tendo apenas teor de Recomendação.

${ }^{11}$ Nos termos do artigo 68.1 da Convenção Americana de Direitos Humanos, os Estados-parte têm o dever de cumprir as decisões nos casos em que forem partes.
} 
[...] la Comisión Interamericana es un órgano competente junto con la Corte "para conocer de los asuntos relacionados con el cumplimiento de los compromisos contraídos por los Estados Partes", por lo que, al ratificar dicha Convención, los Estados Partes se comprometen a atender las recomendaciones que la Comisión aprueba en sus informes. (CORTE INTERAMERICANA DE DIREITOS HUMANOS, 1997, p. 34) $)^{12}$.

Além do mais, no caso Almonacid Arellano e Outros vs. Chile a Corte Interamericana de Direitos Humanos definiu que o controle de convencionalidade não tem como parâmetro apenas os tratados internacionais, mas, também, a própria jurisprudência da Corte. Desse modo, é de se compreender que o Brasil também está vinculado à interpretação, feita pela Corte Interamericana, sobre os limites e o alcance dos dispositivos da Convenção Americana de Direitos Humanos. Nos termos da decisão:

Em outras palavras, o Poder Judiciário deve exercer uma espécie de “controle de convencionalidade” entre as normas jurídicas internas aplicadas a casos concretos e a Convenção Americana sobre Direitos Humanos. Nesta tarefa, o Poder Judiciário deve levar em conta não apenas o tratado, mas também a interpretação que a Corte Interamericana, intérprete última da Convenção Americana, fez do mesmo. 125. Nesta mesma linha de ideias, esta Corte estabeleceu que, "[s]egundo o Direito Internacional, as obrigações por este impostas devem ser cumpridas de boa fé e o Direito Interno não pode ser invocado para justificar seu descumprimento”. (CORTE INTERAMERICANA DE DIREITOS HUMANOS, 2006, p. 52).

Assim o sendo, é de se compreender que ambos os precedentes acima enunciados são vinculantes ao Brasil. Assim, se o Estado brasileiro, voluntariamente, aceita fazer parte do Sistema Interamericano de Direitos Humanos (e, em especial, aceita submeter-se à jurisdição da Corte Interamericana), é de se esperar que, enquanto Estado-parte, deva atuar com base na boa-fé objetiva e, também, com base na máxima do pacta sunt servanda.

Desse modo, sendo parte da Organização dos Estados Americanos, e, também, parte da Convenção Americana dos Direitos Humanos, é obrigação do Estado brasileiro atuar em compasso, empenhando seus maiores esforços para cumprir as deliberações da Comissão Interamericana (RAMOS, 2016, p. 239) e, além disso, compatibilizar com a jurisprudência da Corte Interamericana sua normativa interna (LIRA, 2016, p. 36-40).

Outrossim, não é de se admitir que os Estados encarem o Direito Internacional dos Direitos Humanos como um empecilho ao desenvolvimento nacional. Pelo contrário, a expansão da jurisdição internacional não ocorre em detrimento dos Estados, mas sim com a coparticipação das jurisdições nacionais (TRINDADE, 2017, p. 57).

\footnotetext{
12 “[...] a Comissão Interamericana é um órgão competente junto com a Corte 'para ouvir os assuntos relacionados ao cumprimento dos compromissos assumidos pelos Estados Partes’ e, portanto, ao ratificar a dita Convenção, os Estadosparte se comprometem a cumprir as recomendações que a Comissão aprova em seus relatórios.” (tradução nossa).
} 
A internacionalização dos direitos humanos é um processo que deve ocorrer, também, a partir da jurisdição dos Estados. Ainda que a decisão da Corte Interamericana não tenha sido direcionada ao Brasil, este, enquanto membro do Sistema Interamericano de Direitos Humanos, deve prestigiar a jurisdição internacional e não tentar escapar às obrigações internacionais com as quais previamente anuiu.

No mais, uma última crítica à decisão do Superior Tribunal de Justiça diz respeito, especificamente, ao seguinte trecho do acórdão do tribunal brasileiro:

\begin{abstract}
Ainda que existisse decisão da Corte (IDH) sobre a preservação dos direitos humanos, essa circunstância, por si só, não seria suficiente a elidir a deliberação do Brasil acerca da aplicação de eventual julgado no seu âmbito doméstico, tudo isso por força da soberania que é inerente ao Estado (BRASIL, 2017, p. 3).
\end{abstract}

A presente controvérsia é, a bem da verdade, uma síntese de tudo que já foi analisado acima. Primeiramente, como já examinado, não é de competência do Judiciário nacional aplicar a Margem de Apreciação. Além disso, caso houvesse uma decisão da Corte Interamericana envolvendo o Brasil e decidindo a respeito da inconvencionalidade do crime de desacato, não haveria que se falar em possibilidade de o Estado brasileiro deliberar a respeito da aplicação desta sentença.

O Brasil é parte da Convenção Americana de Direitos Humanos e, portanto, nos termos do artigo 68.1 desta normativa, tem o dever de cumprir a decisão da Corte Interamericana em todo caso em que for parte. Caso o Brasil não esteja satisfeito em ser membro do Sistema Interamericano de Direitos Humanos, deve denunciar os tratados que ratificou e promulgou. Enquanto não ocorrer a denúncia, o Brasil é obrigado perante as decisões exaradas pela Corte Interamericana.

Também não há que se falar em necessidade de homologação da sentença da Corte Interamericana perante o Superior Tribunal de Justiça, tal qual sentença estrangeira fosse. Decisão de Corte Internacional não é sentença estrangeira e, portanto, dispensa processo de homologação. Tratase de entendimento do próprio Superior Tribunal de Justiça (BRASIL, 2008); decisão internacional proferida contra o (ou a favor do) Brasil é aplicável de pronto.

Ademais, vê-se que não se está, propriamente, diante do debate relativo ao "Duplo Controle”, em que se vislumbra compatibilidade entre a decisão do Supremo Tribunal Federal que entende pela constitucionalidade de norma nacional e a decisão da Corte Interamericana de Direitos Humanos que entende pela inconvencionalidade da mesma norma (RAMOS, 2016, p. 403-406). O que o acórdão do Superior Tribunal de Justiça alega é que, ainda que seja proferida uma decisão da Corte Interamericana a respeito do tema (desacato), existe espaço para deliberação nacional, tendo em vista que o Brasil é soberano (BRASIL, 2017, p. 3). 
Esse entendimento carece de validade jurídica. Caso seja proferida sentença contra o Brasil pela Corte Interamericana de Direitos Humanos, é dever do País cumprir tal decisão. Inexistindo hierarquia entre as cortes internacional e nacional (TRINDADE, 2017, p. 60), não há que se falar em posterior deliberação do Brasil a respeito do cumprimento de sentença da Corte Interamericana. É responsabilidade brasileira cumprir a decisão internacional (NEVES, 2009, p. 134).

Mais que isso, a alegação de que o Brasil é soberano não é impedimento à obrigatoriedade do Direito Internacional. Há muito já se superou o aparente paradoxo entre a soberania e a submissão dos Estados às normas internacionais (MENEZES, 2013, p. 137). É exatamente a soberania do Brasil que o habilita a ser parte perante tratados internacionais e é justamente em virtude de sua soberania que o Brasil se compromete com essas normas. Trata-se de compreensão firmada no Caso Lótus da Corte Permanente Internacional de Justiça: “[...] the rules of law binding upon States therefore emanate from their own free will as expressed in conventions or by usages generally accepted as expressing principles of law [...]” (PERMANENT COURT OF INTERNATIONAL JUSTICE, 1927, p. 18) $)^{13}$.

Assim, em total oposição ao que foi utilizado como fundamento da decisão do Superior Tribunal de Justiça, compreende-se que é em razão da soberania do Brasil que as decisões da Corte Interamericana pautadas na Convenção Americana de Direitos Humanos (da qual o Brasil é parte) tornam-se obrigatórias. Em síntese: caso houvesse decisão da Corte Interamericana de Direitos Humanos contra o Brasil, o Estado brasileiro estaria obrigado a cumpri-la independentemente de deliberações e ratificações do Superior Tribunal de Justiça ou de quaisquer outras instâncias do Judiciário brasileiro.

\section{CONSIDERAÇÕES FINAIS}

A democracia no Brasil, assim como no restante da América Latina, ainda está em fase de recomposição (ou, quiçá, ainda em período de formação) (MAINWARING; PÉREZ-LIÑÁN, 2013, p. 36). Além disso, ao menos no caso brasileiro, é possível apontar a conclusão de algumas pesquisas que correlacionam a atuação do Poder Judiciário com os interesses dos regimes de exceção, agindo, por vezes, de forma a legitimar as práticas do projeto autoritário mediante decisões coniventes ou de

\footnotetext{
13 “As normas vinculantes aos Estados, portanto, emanam de sua própria vontade conforme expressa em convenções ou por costumes aceitos representativos de princípios normativos”.
} 
comportamentos permissivos com as arbitrariedades praticadas (SCHINKE; SILVA FILHO, 2016, p. 54-55).

Desse modo, ao menos para alguns, permanece a desconfiança quanto à complacência das decisões dos tribunais brasileiros com as autoridades públicas, em especial aqueles pronunciamentos que restringem direito humano tão íntimo à prática democrática, como é o caso da liberdade de expressão.

Nesse sentido, indo à margem do debate a respeito da legitimidade do crime de desacato, pode-se afirmar que o Judiciário brasileiro tem grande responsabilidade e, além disso, possui o dever de fundamentar de forma válida as decisões que porventura possam ser interpretadas como restrição aos direitos comunicativos. Seja a liberdade de expressão maculada ou não pelo crime de desacato, é preciso que o Poder Judiciário, ao condenar um indivíduo por sua prática, considere a carga substantiva que tal punição possui. Isso ocorre, em especial, por conta do histórico político brasileiro.

Nesses termos, tem-se que o presente artigo se debruçou sobre uma decisão específica de um dos órgãos do Judiciário nacional que chancelou a (e declarou a validade normativa da) punição pela prática do desacato. Revisitando o problema enunciado na introdução, questionou-se: é juridicamente válida a utilização da técnica da Margem de Apreciação pelo STJ em sede do Habeas Corpus 270.269-MS? A hipótese levantada por esta pesquisa é a de que a decisão é juridicamente inválida, pela utilização incorreta da técnica e pelo fato de o Brasil estar sujeito ao Sistema Interamericano de Direitos Humanos, que não adota a técnica nos mesmos moldes que o Sistema Europeu.

É possível afirmar que a hipótese acima foi confirmada ao longo da pesquisa. Como visto, a decisão do STJ, em razão dos fundamentos levantados, mostra-se problemática e, até mesmo, antijurídica. Conforme exposto, a utilização da Margem de Apreciação pelo Superior Tribunal de Justiça se deu em completo descompasso com a própria estrutura do instituto, bem como com as normas referentes à Convenção Americana de Direitos Humanos e a jurisprudência da Corte Interamericana de Direitos Humanos. Por ser seu integrante, o Brasil não pode driblar o Sistema Interamericano de Direitos Humanos, ignorando as normas a que está sujeito, e aplicar a técnica da Margem de Apreciação em suas decisões nacionais.

Sendo assim, em razão destes defeitos, tem-se que a decisão em comento abre espaço à interpretação de que tais fundamentos foram utilizados apenas para legitimar um posicionamento arbitrário e, indiretamente, permite que as sombras da desconfiança sobre o papel do Judiciário no projeto democrático do Brasil ressurjam. 
Não se ignora que muitas vezes (até mesmo na maioria delas) a punição pelo desacato ocorre em razão de práticas com propósitos exclusivamente ofensivos. Mesmo assim, em razão das cicatrizes deixadas pela história nacional, é preciso que o Judiciário reconheça sua responsabilidade com a implementação democrática no País e assuma o dever de fundamentar de forma válida e exaustiva suas decisões.

\section{REFERÊNCIAS}

ALEXY, Robert. Teoria dos Direitos Fundamentais. Tradução Virgílio Afonso da Silva. 2. ed. São Paulo: Malheiros Editores, 2011.

BALTAZAR JUNIOR, José Paulo. Crimes Federais. 11. ed. São Paulo: Saraiva, 2017.

BARBOSA MOREIRA, José Carlos. Temas de Direito Processual: Segunda Série. 2. ed. São Paulo: Saraiva, 1988.

BRASIL. Superior Tribunal de Justiça. Habeas Corpus no 270.269-MS. Relator: Ministro Reynaldo Soares da Fonseca - Terceira Seção. Brasília, decisão de 29 jun. 2017, publicação de 30 jun. 2017. Disponível em: <https://goo.gl/14taya>. Acesso em: 27 mar. 2018.

BRASIL. Superior Tribunal de Justiça. Recurso Especial $\mathbf{n}^{\mathbf{0}}$ 1640084/SP. Relator: Ministro Ribeiro Dantas - Quinta Turma. Brasília, decisão de 19 de dez. 2016, publicação de 01 fev. 2017. Disponível em: <https://goo.gl/Ui5nP7>. Acesso em: 27 mar. 2018.

BRASIL. Superior Tribunal de Justiça. Sentença Estrangeira Contestada $\mathbf{n}^{0}$ 2.707-NL. Relator: Ministro Francisco Falcão. Brasília, decisão de 03 dez. 2008, publicação de 19 fev. 2009. Disponível em: <https://goo.gl/89EphE>. Acesso em: 27 mar. 2018.

CANOtILHO, José Joaquim Gomes. Direito Constitucional e Teoria da Constituição. 2. ed. Coimbra: Livraria Almedina, 1998.

CAROZZA, Paolo G. Subsidiarity as a Structural Principle of International Human Rights Law. American Journal of International Law, vol. 97, 2003. Disponível em: <https://goo.gl/PXenKY>. Acesso em: 27 mar. 2018.

CARVALHO, Lucas Borges de. A Censura Política à Imprensa na Ditadura Militar: Fundamentos e Controvérsias. Revista da Faculdade de Direito UFPR, Curitiba, vol. 59, n. 1, 2014. Disponível em: <https://goo.gl/tDWq7S>. Acesso em: 30 mar. 2018.

CÔRREA, Paloma Morais. Corte Interamericana de Direitos Humanos: Opinião Consultiva 4/84 - A Margem de Apreciação chega à América. Revista de Direito Internacional, Brasília, v. 10, n. 2, 2013. Disponível em: <https://goo.gl/xrrNcA>. Acesso em: 29 mar. 2018.

CORTE INTERAMERICANA DE DIREITOS HUMANOS. Caso Artavia Murillo e Outros (“Fecundação In Vitro”) vs. Costa Rica. Sentença de 28 de novembro de 2012 (Exceções 
Preliminares, Mérito, Reparações e Custas). 2012. Disponível em: <https://goo.gl/Me9Frm>. Acesso em: 27 mar. 2018.

CORTE INTERAMERICANA DE DIREITOS HUMANOS. Caso Almonacid Arellano e Outros vs. Chile. Sentença de 26 de Setembro de 2006 (Exceções Preliminares, Mérito, Reparações e Custas). 2006. Disponível em: <https://goo.gl/BQb62F>. Acesso em: 27 mar. 2018.

CORTE INTERAMERICANA DE DIREITOS HUMANOS. Caso Loayza Tamayo vs Peru. Sentencia de 17 de Septiembre de 1997. Disponível em: <https://goo.gl/rst8BL>. Acesso em: 27 mar. 2018.

CORTE INTERAMERICANA DE DIREITOS HUMANOS. Caso Palamara Iribarne vs. Chile. Sentencia de 22 de Noviembre de 2005. 2005. Disponível em: <https://goo.gl/1zGxQ2>. Acesso em: 27 mar. 2018.

CORTE INTERAMERICANA DE DIREITOS HUMANOS. Opinión Consultiva OC-4/84 Propuesta de Modificación a la Constitución Política de Costa Rica Relacionada con la Naturalización. 1984. Disponível em: <https://goo.gl/G16LF>. Acesso em: 27 mar. 2018.

COUNCIL OF EUROPE. Protocol No. 15 amending the Convention on the Protection of Human Rights and Fundamental Freedoms. 2013. Disponível em: <https://goo.gl/mCV1Dz>. Acesso em: 27 mar. 2018.

GADAMER, Hans-Georg. Truth and Method. 2. ed. London: Continuum, 2004.

GOMES, Eduardo Biacchi; GONÇALVES, Ane Elise Brandalise. O Controle de Convencionalidade, a Convenção Americana de Direitos Humanos e o Crime de Desacato. Revista Jurídica da Presidência, v. 18, n. 114, 2016. Disponível em: <https://goo.gl/d3SMNi>. Acesso em: 30 mar. 2018.

GRECO, Rogério. Código Penal Comentado. 11. ed. Niterói: Impetus Editora, 2017.

GREER, Steven. The Margin of Appreciation: Interpretation and Discretion Under the European Convention on Human Rights. Human Rights Files n. 17, Council of Europe Publishing, 2000. Disponível em: <https://goo.gl/QcBr3q>. Acesso em: 27 mar. 2018.

GROSS, Oren; AOLÁIN, Fionnuala Ní. From Discretion to Scrutiny: Revisiting the Application of the Margin of Appreciation Doctrine in the Context of Article 15 of the European Convention on Human Rights. Human Rights Quarterly, vol. 23, n. 3, Aug. 2001. Disponível em: <https://goo.gl/C5fFQc>. Acesso em: 27 mar. 2018.

GUZMAN, Andrew T.; MEYER, Timothy L. International Soft Law. Journal of Legal Analysis, vol. 2, n. 1, 2010. Disponível em: <https://goo.gl/XqVNdw>. Acesso em: 27 mar. 2018.

HABERMAS, Jürgen. Constitutional Democracy: A Paradoxical Union of Contradictory Principles? Political Theory, vol. 29, n. 6, 2001. Disponível em: <https://goo.gl/xKmjNr>. Acesso em: 30 mar. 2018. 
HOFFMANN, Lord. The Universality of Human Rights. Judicial Board Annual Lecture of 19 March 2009, Courts and Tribunals Judiciary, 2009. Disponível em: <https://goo.gl/YnJr7e>. Acesso em: 27 mar. 2018.

HUTCHINSON, Michael R. The Margin of Appreciation Doctrine in the European Court of Human Rights. The International and Comparative Law Quarterly, British Institute of International and Comparative Law, vol. 48, n. 3, 1999. Disponível em: <https:/goo.gl/thcEti>. Acesso em: 27 mar. 2018.

KELSEN, Hans. A Democracia. Tradução Ivone Benedetti, Jefferson Camargo, Marcello Cifolla, Vera Barkow. São Paulo: Martins Fontes, 2000.

LETSAS, George. Two Concepts of the Margin of Appreciation. Oxford Journal of Legal Studies, vol. 26, n. 4, 2006. Disponível em: <https://goo.gl/JXC1oL>. Acesso em: 27 mar. 2018.

LIRA, Yulgan Tenno de Farias. Controle de Convencionalidade: A Tutela Coletiva dos Tratados Internacionais de Direitos Humanos. João Pessoa: Ideia, 2016.

LOPES SALDANHA, Jânia Maria; MORAIS BRUM, Márcio. A Margem Nacional de Apreciação e sua (In)aplicação pela Corte Interamericana de Direitos Humanos em Matéria de Anistia: Uma Figura Hermenêutica a Serviço do Pluralismo Ordenado? Anuário Mexicano de Derecho Internacional, vol. 15, 2015. Disponível em: <https:/goo.gl/MnkKS1>. Acesso em: 27 mar. 2018.

MACHADO, Jónatas E. M. Liberdade de Expressão: Dimensões Constitucionais da Esfera Pública no Sistema Social. Boletim da Faculdade de Direito da Universidade de Coimbra. Coimbra: Coimbra Editora, 2002.

MAINWARING, Scott; PÉREZ-LIÑÁN, Aníbal. Democracies and Dictatorships in Latin America: Emergence, Survival and Fall. New York: Cambridge University Press, 2013.

MEIKLEJOHN, Alexander. The First Amendment is an Absolute. The Supreme Court Review, vol. 1961, 1961. Disponível em: <https://goo.gl/WZSBcz>. Acesso em: 30 mar. 2018.

MENEZES, Wagner. Tribunais Internacionais: Jurisdição e Competência. São Paulo: Saraiva, 2013.

NEVES, Marcelo. Transconstitucionalismo. São Paulo: Editora WMF Martins Fontes, 2009.

ORGANIZAÇÃO DOS ESTADOS AMERICANOS. Declaração de Princípios sobre Liberdade de Expressão de 16 a 27 de outubro de 2000. Washington, 27 out. 2000. Disponível em: <https://goo.gl/QCLLKo>. Acesso em: 23 mar. 2018.

PARRAS, Francisco Javier Mean. Democracy, Diversity and the Margin of Appreciation: A Theoretical Analysis from the Perspective of the International and Constitutional Functions of the European Court of Human Rights. Revista Electrónica de Estudios Internacionales, n. 29, 2015. Disponível em: <https://goo.gl/DhxMEE>. Acesso em: 30 mar. 2018. 
PERMANENT COURT OF INTERNATIONAL JUSTICE. The Case of the S.S. "Lotus". Publications of the Permanent Court of International Justice, Series A, n. 10, 1927. Disponível em: <https://goo.gl/fEcXVm>. Acesso em: 30 mar. 2018.

RAMOS, André de Carvalho. Curso de Direitos Humanos. 4 ed. São Paulo: Saraiva, 2017.

RAMOS, André de Carvalho. Processo Internacional dos Direitos Humanos. 5. ed. São Paulo: Saraiva, 2016.

SARMENTO, Daniel. Liberdade de Expressão, Pluralismo e o Papel Promocional do Estado. Revista Diálogo Jurídico, n. 16, 2007. Disponível em: <https:/goo.gl/myM9Mk>. Acesso em: 20 jan. 2018.

SCHINKE, Vanessa Dorneles; SILVA FILHO, José Carlos Moreira da. Poder Judiciário e Regime Autoritário: Democracia, História Constitucional e Permanências Autoritárias. Revista da Faculdade de Direito UFPR, Curitiba, vol. 61, n. 2, maio/ago. 2016. Disponível em: $<$ https://goo.gl/u7GYYX>. Acesso em: 30 mar. 2018.

SCHLINK, Bernhard. Proportionality. In: ROSENFELD, Michel; SAJÓ, András (Ed.). The Oxford Handbook of Comparative Constitutional Law. Oxford: Oxford University Press, 2012.

SOUZA NETO, Cláudio Pereira de; SARMENTO, Daniel. Direito Constitucional: Teoria, História e Métodos de Trabalho. 2. ed. Belo Horizonte: Fórum, 2014.

TRINDADE, Antônio Augusto Cançado. Os Tribunais Internacionais e a Realização da Justiça. 2. ed. Belo Horizonte: Del Rey, 2017.

TRINDADE, Antônio Augusto Cançado. Tratado de Direito Internacional dos Direitos Humanos. Vol. II. Porto Alegre: Sergio Antonio Fabris Editor, 1999.

VILA, Maria Iglesias. Subsidiarity, Margin of Appreciation and International Adjudication Within a Cooperative Conception of Human Rights. International Journal of Constitutional Law, vol 15, 2, 2017. Disponível em: <https://goo.gl/Ybahya>. Acesso em: 30 mar. 2018.

VILLEY, Michel. O Direito e os Direitos Humanos. Tradução Maria Ermantina de Almeida Prado Galvão. São Paulo: WMF Martins Fontes, 2007. Constituição pela UnB e Mestre em Direito Público pela UFPE.E-mail: rabay@me.com 